\title{
IMPROVING THE QUALITY OF MILK DISPERSION IN A COUNTER-J ET HOMOGENIZER
}

\author{
Kyrylo Samoichuk, Dmytro Zhuravel, Nadiya Palyanichka, Vadim Oleksiienko, Serhii Petrychenko, \\ Natalia Slobodyanyuk, Olga Shanina, Ivan Galyasnyj, Leonora Adamchuk, Vladyslav Sukhenko
}

\begin{abstract}
Homogenization is a necessary process in the production of drinking milk and most dairy products. The specific energy consumption of the most common valve homogenizers reaches $8 \mathrm{~kW} \mathrm{h.t} \mathrm{t}^{-1}$. A promising way to reduce it is the introduction of more effective counter-jet homogenizers. The purpose of these studies is to increase the efficiency of machines of this type through fuller use of their kinetic energy. To achieve this, the design of a ring reflector was developed and experimental studies were carried out to determine its influence on the efficiency of milk fat dispersion in a counter-jet homogenizer. Calculations were made to determine the reflector's design parameters. An installation for experimental research has been developed, in which the required milk pressure is created with the help of compressed carbon dioxide. The dispersive indices of the milk emulsion were determined by computer analysis of milk sample micrographs obtained with an optical microscope and a digital camera using Microsoft Office Excel and Microsoft Visual Studio C\# software using the OpenCV Sharp library. As a result of research, the formula for defining the angle of the reflector top has been determined analytically. Experimental studies proved its validity and allowed determination of the optimal diameter. A comparison of the dependence of the degree of homogenization on the excess pressure in a counter-jet homogenizer proves a $15-20 \%$ increase in the degree of dispersion when using a reflector. At the same time, specific energy consumption does not increase. Comparison of the distribution curves of milk fat globules by size after counter-jet homogenization and homogenization with a reflector suggests that the average diameter of fat globules for the experimental method decreases from 0.99 to $0.83 \mu \mathrm{m}$. This indicates the high quality of the dispersal characteristics of the milk emulsion after processing in a counter-jet homogenizer with a reflector.
\end{abstract}

Keywords: milk; homogenization; homogenizer; counter-jet homogenizers; reflector; degree of dispersion

\section{INTRODUCTION}

Homogenization is a necessary process in the production of drinking milk and most dairy products. The benefits of homogenized products are undeniable: reduced cream sludge, increased milk shelf life, improved taste and sensory properties of dairy products, increased digestion of milk fat and its even distribution throughout the product, etc. (Dhankhar, 2014).

When milk is homogenized, its fat phase is dispersed (fat globules are crushed), as a result of which the average fat particle size decreases from $3-5$ to $0.7-1 \mu \mathrm{m}$ (Walstra, Wouers and Geurts, 2006). This result can be achieved by exposing milk to pressure and velocity via ultrasonic, cavitation, vacuum and high-frequency electrical treatment (Nuzhin and Gladushnyak, 2007; Samoichuk et al., 2016). Taking into account such a wide range of effects on the milk emulsion, dozens of types of homogenizers have been developed, which differ significantly from each other both in their design and principle of action (Dhankhar, 2014; Fialkova, 2006).

A modern homogenizer must have a high efficiency (degree) of homogenization at low energy consumption. Moreover, the high degree of homogenization is crucial, which is confirmed by the fact that the vast majority of homogenizers in processing plants are valvular. When processing milk in such machines, the average diameter of fat globules is $0.75 \mu \mathrm{m}$, and the amount of energy consumed per unit of processed product is the highest among all existing homogenizers (Rayner and Dejmek, 2015). Vacuum, ultrasonic, cavitation, mixing, electrohydraulic, screw, and spunbond devices for homogenization with significantly lower energy consumption have a lower degree of homogenization (Dhankhar, 2014; Fialkova, 2006; Nuzhin and Gladushnyak, 2007). The degree of homogenization is close to that of valve rotor-pulsation and vortex 
homogenizers. But a product that has been processed in a rotary homogenizer has a large fat content, which negatively affects the quality of dairy products made from such milk (Fialkova, 2006).

Two types of high-efficiency jet homogenizers are distinguished, namely: jet, with a separate supply of fat phases (Samoichuk et al., 2020), and counter-jet (Samoichuk, 2008). Such homogenizers, the only ones among existing types, provide the highest speed of flow of the fat globule through the flow of milk plasma. After all, the Weber criterion depends on this value, which is a generalizing indicator for the main factors in the dispersion of the fat phase of milk (Samoichuk et al., 2019). Weber's destruction coincides with the theories of homogenization by N. Baranovsky, P. Rebinder, A. Wittig and $M$. Oreshina, and by Innings' experimental studies (Innings and Trägårdh, 2005; Oreshina, 2010).

A counter-jet homogenizer is not inferior to the valve type regarding the degree of dispersion of milk but has a specific energy consumption $4-5$ times lower (Samoichuk, 2008). This indicates a high potential for hydrodynamic dispersion, which is carried out when jets of milk emulsion collide.

In a study on such a homogenizer, it was found that the disruption of milk fat globules mainly occurs in the central part of the jet collision zone (Samoichuk, 2008). After that, the jets divaricate in a fan shape (circularly). Their speed, and hence kinetic energy, is quite high. But this energy is not used for dispersion, so it reduces the efficiency of the homogenizer.

It is known that the disruption of milk fat globules occurs when a jet of milk collides with a hard surface (Deynichenko et al., 2018; Nuzhin and Gladushnyak, 2007). Concerning counter-jet homogenizers, such a surface may be an annular reflector located in the path of milk flow after the collision.

\section{Scientific hypothesis}

This study hypothesizes that it is possible to increase the dispersion efficiency of a counter-jet homogenizer by installing an annular reflector.

This article aims to evaluate the effectiveness of dispersing milk in a counter-jet homogenizer with a reflector.

To achieve this aim, it is necessary to:

- develop the design of the annular reflector;

- experimentally determine the effect of the main parameters of the counter-jet homogenizer with a reflector on the degree of homogenization of milk;

- evaluate the dispersal indicators of the milk emulsion after homogenization.

\section{MATERIAL AND METHODOLOGY}

\section{Experimental equipment}

For experimental research, the reflector device was designed, the scheme of which is presented in Figure 1 (Samoichuk, 2008).

The device consists of a chamber 15, in which the nozzles 16 are installed. The bottom of the chamber is conical with a slope to the centre, where the hole for removing milk after homogenization is placed. At the top, the chamber is closed with a transparent lid 10 to allow the process to be monitored. The sleeves 17 for adjusting the position of the nozzles with radially located screws allow the distance between nozzles to be changed and their alignment. Nozzles are collapsible and can be replaced.

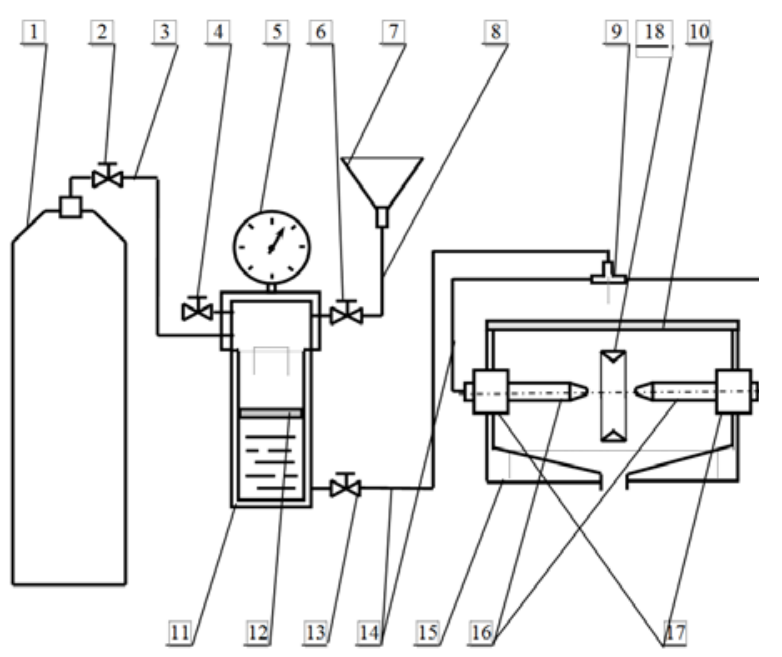

a)

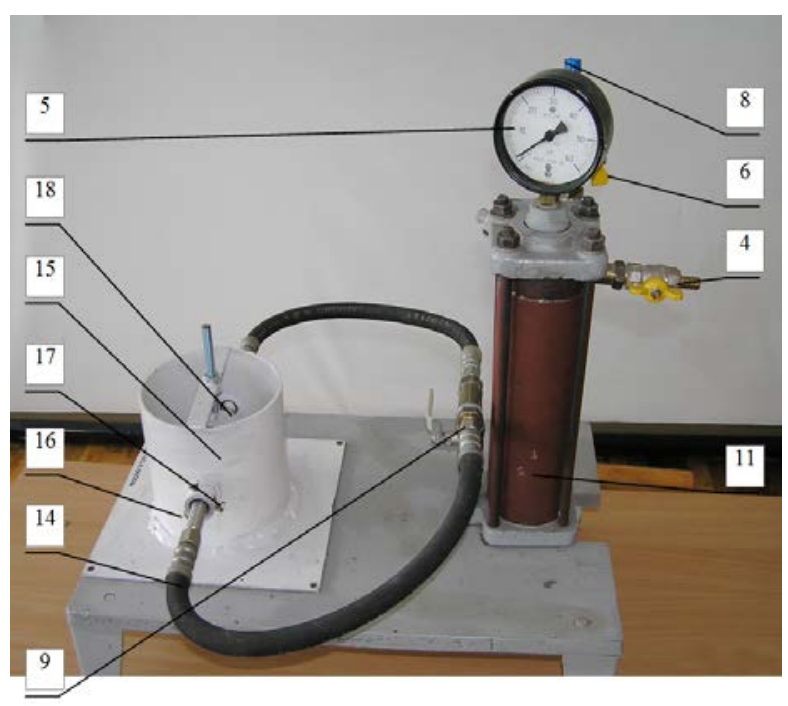

b)

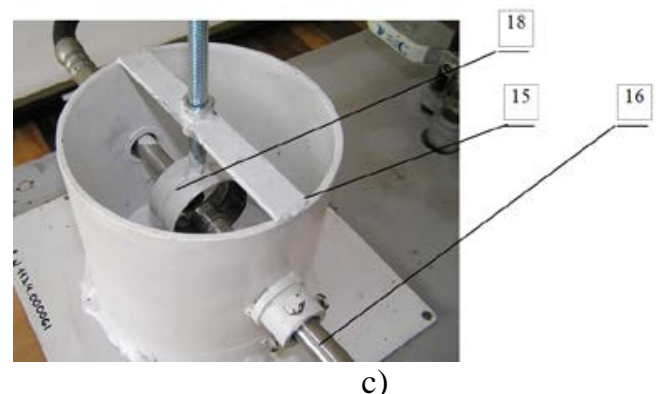

c)

Figure 1 Scheme a), general view b) and chamber c) of the laboratory device for the study of counter-jet homogenization of milk: 1 - gas cylinder; 2 discharge valve; 3 - air duct; 4 - outlet valve; 5 manometer; 6 - filling valve; 7 - funnel; 8 - hose; 9 tee; 10 - cover; 11 - cylinder; 12 - piston; 13 - main valve; 14 - hydraulic hoses; 15 - camera; 16 - nozzles; 17 - bushings for adjusting the position of the nozzles; 18 - reflector. 
The creation of the required milk pressure is achieved by the gas cylinder 1 and cylinder 11 , which are connected by the air duct 3 . The pressure is controlled by the pressure gauge 5 . The discharge valve 2 is used to fill the cylinder with gas from the cylinder. The milk is poured into the cylinder using the funnel 7 , the hose 8 , and the filling valve 6 . The outlet valve 4 is necessary for the release of gas from the cylinder when it is filled with milk. The piston 12 prevents the diffusion of gas into the milk and, thus, a change in its properties.

The cylinder and nozzles are connected by hydraulic hoses 14. The division of the main milk flow from the cylinder into two equal flows is carried out in the tee 9. The main valve 13 is used to supply milk under the required pressure to the nozzles.

When performing the tests, the required volume of milk was poured into the cylinder through the funnel, with filling and outlet valves open. The main valve was kept closed. To create the necessary pressure in the cylinder, a GOST 8050-85 carbon dioxide cylinder was used. After opening the discharge valve (outlet and filling valves closed), carbon dioxide was supplied to the cylinder and the pressure in it increased to the required value. The device uses a manometer with a measurement limit of 100 $\mathrm{kg} / \mathrm{cm}^{2}$, accuracy class 0.75 according to GOST 2405-85. When the main valve was opened, the milk under the required pressure was sent to the nozzles, in which jets were formed. After homogenization, the milk was gravitationally discharged through a hole in the lower part of the chamber.

The main factors of the experimental studies were the excess pressure of the milk supply to the nozzles $\Delta \mathrm{p}$ and the diameter of the nozzle cone $d_{n}$. The distance between the nozzles $a$ was taken to be equal to half the diameter of the nozzle cone (Samoichuk, 2008). The temperature of milk during homogenization was assumed to be $60-70{ }^{\circ} \mathrm{C}$ (Walstra, Wouers and Geurts, 2006). For counter-jet homogenization, the excess pressure is related to the modified Weber criterion $\mathrm{We}^{\mathrm{o}-\mathrm{s}}$ by the ratio:

$$
\mathrm{We}^{\mathrm{o-s}}=\frac{6 \rho_{\mathrm{p}} \cdot \varphi^{2} \cdot \Delta \mathrm{p}}{10^{6} \sigma_{\mathrm{f}-\mathrm{p}} \cdot \rho_{\mathrm{m}}},
$$

Where: $\rho_{\mathrm{p}}, \rho_{\mathrm{m}}-$ density of milk plasma and milk, kg.m ${ }^{-3}$; $\varphi$ - hydraulic coefficient of jet speed; $\sigma_{f-p}-$ surface tension between milk fat and plasma, N.m ${ }^{-1} ; \Delta \mathrm{p}$ - excess milk supply pressure, $\mathrm{Pa}$.

For the experimental studies, whole milk was used (DSTU 8553, 2015), with a density of $1027-1023$ kg.m ${ }^{-3}$, and fat content of $2.5-4.4 \%$.

\section{Statistical analysis}

The degree of homogenization of milk was determined by the formula (Loncin and Merson, 1979; Nuzhin and Gladushnyak, 2007):

$$
\mathrm{Hm}=\frac{\mathrm{d}_{0}}{\mathrm{~d}_{\mathrm{k}}},
$$

Where:

$\mathrm{d}_{0}, \mathrm{~d}_{\mathrm{k}}$ - average diameter of fat globules before and after homogenization, $\mu \mathrm{m}$.

Average diameters of fat globules and other dispersive indices of the milk emulsion were determined by computer analysis of the micrographs of milk samples obtained with an optical microscope and a Mustek Wcam 300 digital camera (resolution 640×480) (Samoichuk et al., 2020). Each experiment was repeated three times. From each experiment, three samples were selected and two dilutions were prepared from each sample. Six characteristic microscope field of view photos were selected from each dilution. Thus, 36 microscope fields of view were analysed to determine the statistical characteristics of milk.

The geometric characteristics of fat globules were analysed based on digital image analysis of the micrographs obtained.

The number of fat globules in the microscope field of view and their diameter were determined in the process of calculations. The average diameter of fat globules was determined by the statistical method of power average (arithmetic mean).

The qualitative uniformity of the measured data set was estimated by the coefficient of variation V. For dispersed indicators of milk fat globules, the coefficient of variation is sufficient for V >0.6 (Haponiuk, Zander and Probola, 2015; Di Marzo, Cree and Barbano, 2016). When this condition is satisfied, the values of $\mathrm{V}$ are not given separately.

For this purpose, a software module has been developed that is implemented in Microsoft Visual Studio 2010 based on C\# using the OpenCV Sharp library set 4.2.0. The exported numerical data and calculation of the sample statistics were performed in Microsoft Office Excel 2010.

A McBrain VA 318 electric wattmeter (Volga Region Power Equipment Plant, Russia) was used to record power.

\section{RESULTS AND DISCUSSION}

\section{The rationale for the design of the reflector}

For efficient operation of the annular reflector, the liquid flows after their collision with the annular reflector mustn't intersect with the main jets of milk (coming out of the nozzles) (Fialkova, 2006; Innings and Trägårdh, 2005). Otherwise, there will be a violation of the continuity of the main jets and a decrease in the degree of dispersion of milk emulsions. To meet these requirements, the annular reflector in the radial cross-section must have the shape of an equilateral triangle, the vertex of which faces inwards of the annular reflector. With this design, the jets reflected from the surfaces of the reflector are removed outside the main jets of milk, which is necessary to prevent their crossing (Figure 2).

To prevent the intersection of the main jets of milk with those reflected from the reflector, it is necessary to calculate the angle $\beta$ (Figure 3). 


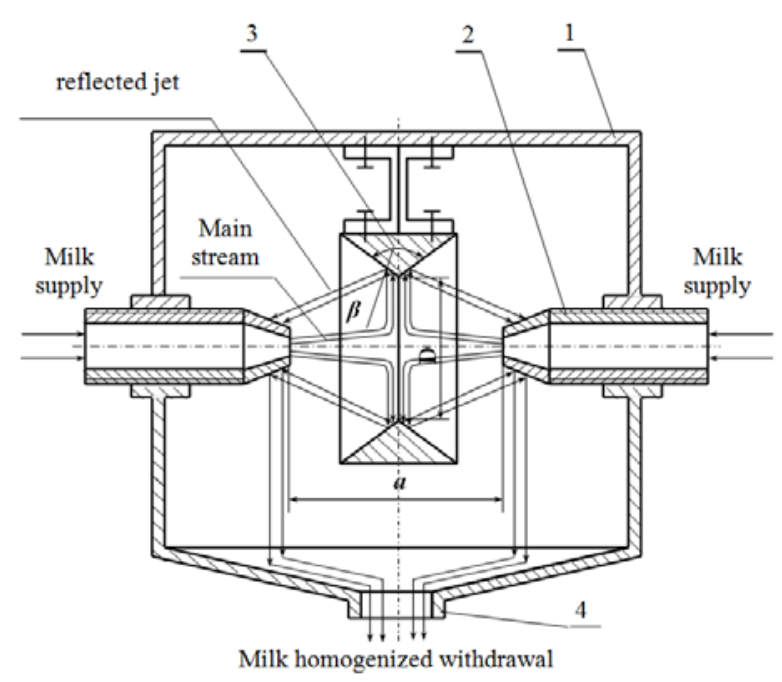

Figure 2 Scheme of the location of the annular reflector and direction of milk flows in the process of homogenization. Note: 1 - camera body; 2 - nozzle; 3 - annular reflector; 4 - hole for draining homogenized milk; D - diameter of the reflector; $\beta$ - the angle of the reflector; $a$ - the distance between the nozzles.

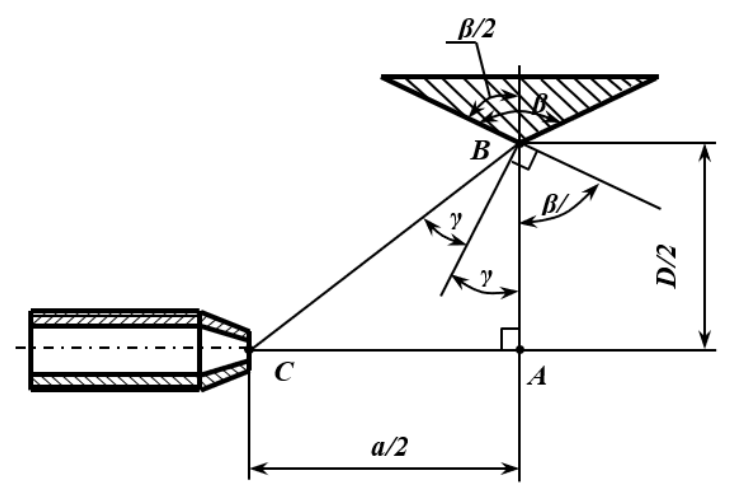

Figure 3 Calculation scheme for determining the angle $\beta$ of the annular reflector.

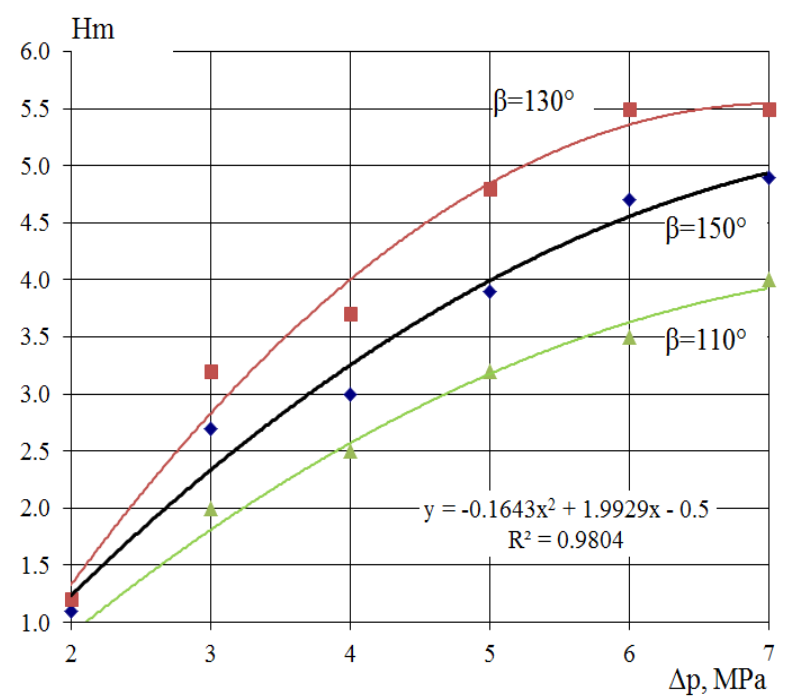

Figure 4 Dependence of the influence of excess pressure and angle of the reflector on the degree of homogenization at $70{ }^{\circ} \mathrm{C}$.

$$
\beta=180^{\circ}-\operatorname{arctg} \frac{\mathrm{a}}{\mathrm{D}} .
$$

The counter-jet homogenizer with a reflector works as follows. Whole milk is fed into the nozzles under the required pressure, which depends on the required degree of homogenization. After passing through the nozzle cones, the milk jets meet, while the fat fraction of milk is dispersed and mixed. The coaxial arrangement of the jets allows the fullest use of the kinetic energy of the fluxes for grinding the dispersed phase (Huppertz, 2011; Samoichuk, 2008). After collision and homogenization, the product flow diverges in a fan shape perpendicular to the direction of the jets and hits the annular reflector. This results in the final grinding and partial mixing of the dispersed phase of the mixture (Nuzhin and Gladushnyak, 2007). After contact with the annular reflector, the mixture is reflected from it and enters the housing of the homogenization device, where it is gravitationally removed from the machine. Moreover, due to the properly calculated angle of the annular reflector $\beta$, the product streams after contact with the annular reflector are reflected outside the jets coming out of the nozzles, so that there is no intersection of the flows of nonhomogenized and homogenized products. Thus, in the counter-jet homogenizer with a reflector, dispersion of the fat phase of milk occurs in two stages: when the jets collide with each other and when the secondary jets collide with the reflector. This allows fuller use of the energy of the flow of milk.

\section{Results of experimental studies}

To determine the effect of excess pressure and the angle of the reflector on the degree of homogenization, an experiment was performed, the results of which are shown in Figure 4.

With increasing excess pressure, the degree of homogenization increases with parabolic dependence. At higher values of excess pressure, the growth of the response function $(\mathrm{Hm})$ slows down. The prediction performed by the computer program Microsoft Office Excel 2010 (Lawrence, Klimberg and Lawrence, 2009) shows a maximum achievable degree of homogenization of 5.6 at an overpressure value of 7.4 - 7.5 MPa.

The optimal value of the angle of the reflector, calculated by the formula (3), is $130^{\circ}$. This achieves the highest degree of dispersion of the fat phase of milk - milk flow after reflection from the surfaces of the reflector is directed to the nozzle body and does not interfere with the free exit of the main jet from the nozzles. At an angle of the reflector $\beta=150^{\circ}$, the flow of milk strikes further on the body of the nozzles. In this case, due to the greater distance, the jet speed becomes smaller, so the efficiency of additional homogenization decreases. At an angle of the reflector $\beta=110^{\circ}$, the milk flow after the reflector intersects with the jets coming out of the nozzles, so the continuity of the milk flow is disturbed and its normal velocity component falls, so the decrease in the degree of homogenization is more significant. 


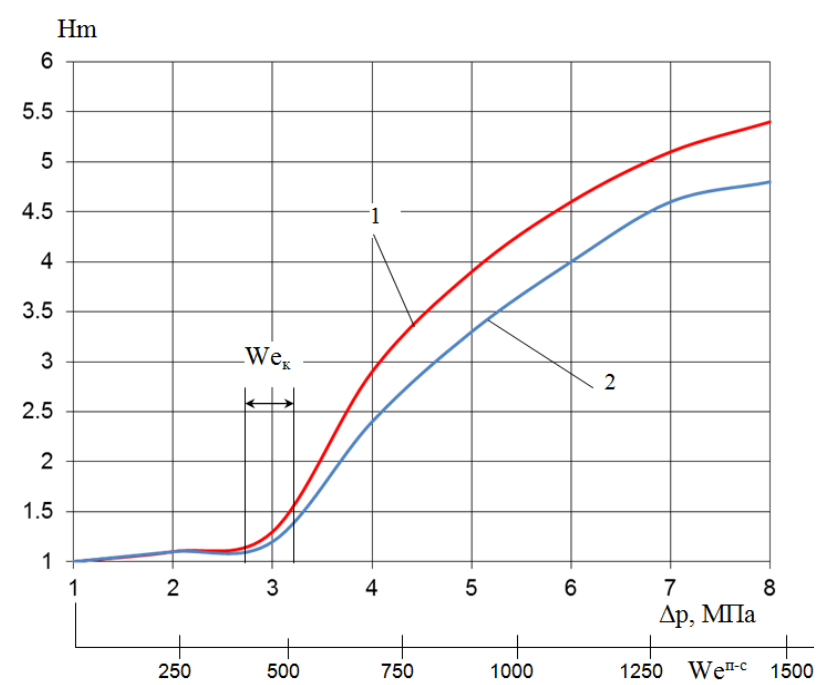

Figure 5 Comparison of the dependence of the degree of homogenization on excess pressure and the modified Weber criterion (at $\mathrm{T}=70{ }^{\circ} \mathrm{C}, \mathrm{a}=0.56 \mathrm{~mm}, \mathrm{~d}_{\mathrm{c}}=1 \mathrm{~mm}$ ): 1 - counter-jet homogenizer with a reflector; 2 - counterjet homogenizer without a reflector.

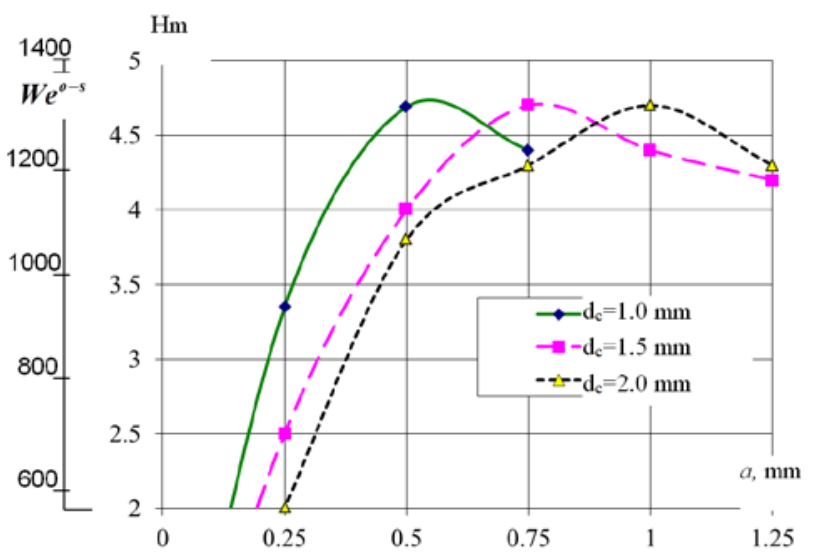

Figure 6 Dependence of the degree of homogenization and the modified Weber criterion on the distance between nozzle cones.

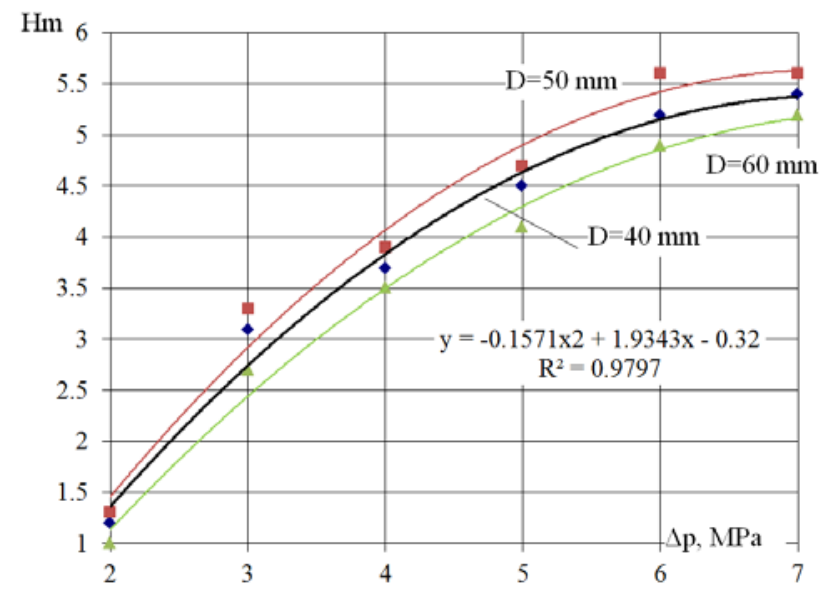

Figure 7 Results of experimental determination of the degree of homogenization depending on the pressure and diameter of the reflector.
The deviation of the values of the experimental curve of the modernized homogenizer in comparison to the homogenizer without a reflector is $15-20 \%$. Indeed, the increase in the degree of homogenization with the reflector installed is due to more complete use of the kinetic energy of the milk flow in additional contact with the reflector and the nozzle housing.

Approximating the data of Figures 5 with a straight line, we obtain an expression that is identical in content to the known dispersion formula (Loncin and Merson, 1979):

$$
\mathrm{Hm}=0.9 \cdot 10^{-6} \Delta \mathrm{p} \cdot \varphi^{2}
$$

The coefficient of determination $\left(\mathrm{R}^{2}\right)$ in the range of $2.5<\mathrm{Hm}<6.0$ is $95 \%$, and at $\Delta \mathrm{p}=5.0-6.0 \mathrm{MPa}$ and a degree of homogenization of $4.5-5.2$, the difference between theoretical and practical data is minimal. At $\Delta \mathrm{p}=6.5 \mathrm{MPa}$, this difference reaches $6 \%$ and with a further increase in excess pressure, it is possible to predict its rapid increase. In the range $\Delta \mathrm{p}=2-3 \mathrm{MPa}$, there is an intensive increase in the degree of grinding of the fat phase of milk. Here, the deviation of experimental data from the specified (approximated) dependence is maximal. At the value of $\Delta \mathrm{p}<2 \mathrm{MPa}$, homogenization practically does not occur.

The critical value of the Weber criterion (the beginning of the grinding of the fat phase) corresponds to the range of excess pressure of $1.8-2.2 \mathrm{MPa}$, at which $\mathrm{We}=500-600$.

Therefore, the optimal parameters of counter-jet homogenization for $\mathrm{d}_{\mathrm{c}}=1 \mathrm{~mm}$ are: $a=0.5 \mathrm{~mm}$ and $\mathrm{T}=60-65{ }^{\circ} \mathrm{C}$. The value of excess pressure depends on the required degree of homogenization and is $\Delta \mathrm{p}=6.5 \mathrm{MPa}$ at $\mathrm{Hm}=5.0$.

The results of experimental determination of the degree of homogenization and Weber criterion, with nozzle cone diameters of $1.0,1.5$, and $2.0 \mathrm{~mm}$, depending on the distance between the nozzles cones, are shown in Figure 6 . The diameter of the cone does not affect the maximum degree of homogenization.

It should be noted that at $\boldsymbol{a}<\boldsymbol{d}_{\boldsymbol{c}} / \mathbf{2}$ the degree of homogenization is higher by $15-40 \%$ than that theoretically calculated (Samoichuk, 2008), and the velocity of the jets at $\boldsymbol{a}<\boldsymbol{d}_{\boldsymbol{c}} / \boldsymbol{2}$ corresponds to the calculated data. This can be explained by a more sudden change in the velocity of the fat globules after the collision of jets (which leads to an increase in the velocity difference between the fat globules and the surrounding plasma), due to the strict limitation of boundaries of the jet flow that is diverted by the edges of the nozzles (Samoichuk and Kovalyov, 2013). Therefore, the optimal location of the nozzles is at a distance equal to half the diameter of the nozzle cone (Samoichuk, 2008).

To determine the diameter of the annular reflector of the counter-jet homogenizer, the experimental study was conducted with reflector diameters $\mathrm{D}=40,50$, and $60 \mathrm{~mm}$. The results are shown in Figure 7.

It is optimal to use a reflector with a diameter of $50 \mathrm{~mm}$ as we obtain the maximum degree of fat dispersion. At $\mathrm{D}=40 \mathrm{~mm}$, the degree of homogenization decreases by $0.2-0.3$, that is by $5 \%$. This can be explained as follows. When using a reflector with a smaller diameter to comply 
with the formula (3), the angle $\beta$ decreases and the impact on the reflector becomes more sliding, which reduces the degree of homogenization. At $\mathrm{D}=40 \mathrm{~mm}$, the degree of homogenization decreases by $0.5-0.6$, i.e. by $10 \%$. This is due to the increase in loss of flow velocity before the collision with the reflector.

Changes in the fractional composition of fat globules after counter-jet homogenization (Samoichuk, 2008) (at $\left.\mathrm{T}=65{ }^{\circ} \mathrm{C}, \Delta \mathrm{p}=3.5 \mathrm{MPa}\right)$ and comparing them with homogenization with a reflector (at a pressure of $4 \mathrm{MPa}$ and $\mathrm{T}=65^{\circ} \mathrm{C}$ ) and whole milk (Dhankhar, 2014; Nuzhin and Gladushnyak, 2007; Oreshina, 2010; Haponiuk, Zander and Probola, 2015) are graphically represented in Figure 8, and micrographs of fat globules are shown in Figure 9.

Milk before homogenization is characterized by the following parameters: average diameter of fat globules $\mathrm{d}_{\mathrm{k}}=2.49 \mathrm{~mm}$, dispersion $\sigma=1.66$, coefficient of variation

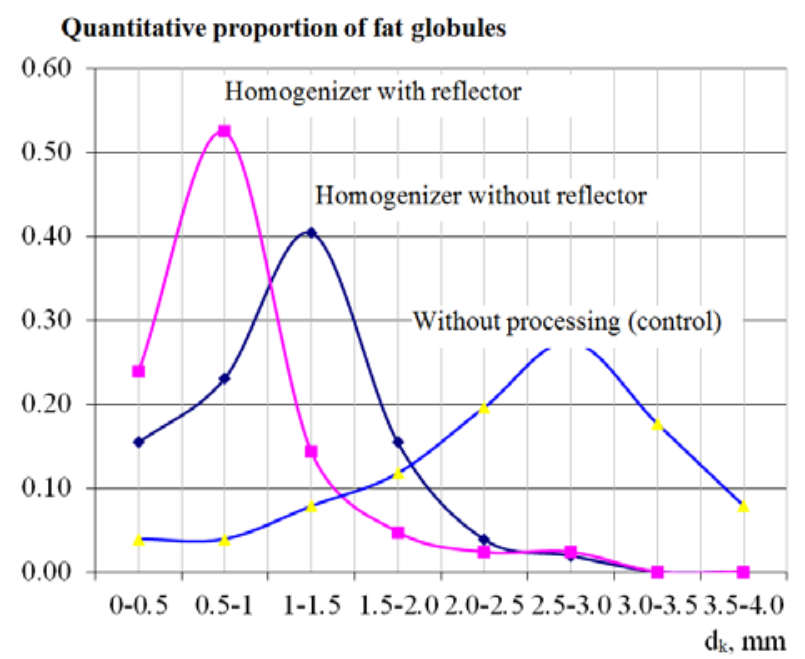

Figure 8 Differential distribution of fat globules of milk.

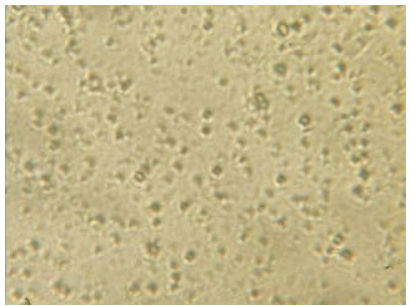

a)

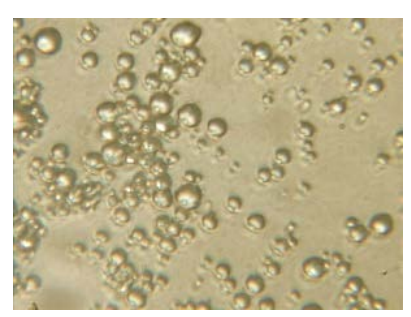

c) b)

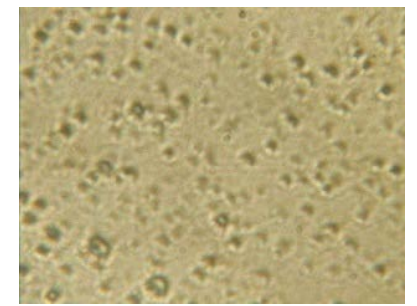

Figure 9 Photomicrographs of milk samples (400× magnification). Note: a) after counter-jet homogenization with a reflector at $\Delta \mathrm{p}=4.0 \mathrm{MPa}$; b) after counter-jet homogenization at $\Delta \mathrm{p}=4.0 \mathrm{MPa}$; c) raw milk. (the share of scattering of the trait relative to the average) $\mathrm{V}=67 \%$ (Di Marzo, Cree and Barbano, 2016; Floury, Desrumaux and Lardieres, 2000; Hussain et al., 2017). Respectively for milk after counter-jet and countercurrentjet homogenization with a reflector: $\mathrm{d}_{\mathrm{k}}=0.99 \mathrm{~mm}$ and 0.83 $\mathrm{mm}, \sigma=0.51$ and $0.47, \mathrm{~V}=51 \%$ and $56 \%$.

The value of the coefficients of variation indicates the reliability of the data sample.

The average diameter of the fat globules for the counterjet homogenization treatment with the reflector decreased by $19 \%$ (from 0.99 to $0.83 \mu \mathrm{m}$ ) compared to that with the non-upgraded homogenizer. The dispersion value also decreased, which indicates the advantage of counter-jet homogenization with a reflector.

\section{CONCLUSION}

The design of the annular reflector has been developed to ensure the condition of free flow after collision with the surface of the reflector. The reliability of the theoretically obtained dependences for determining the angle of the reflector has been confirmed. It is proved that it is optimal to use a reflector diameter of about $50 \mathrm{~mm}$.

When using a counter-jet homogenizer, it is possible to achieve a degree of homogenization of 5.6 at an excess pressure of $7.4-7.5 \mathrm{MPa}$. The degree of homogenization when installing an annular reflector increases by $15-20 \%$. Moreover, such an increase in quality is provided without increasing energy consumption.

A comparison of the data on the distribution of milk fat globules by size after counter-jet homogenization and homogenization with a reflector suggests that the average diameter of fat globules for the experimental method is $19 \%$ smaller. The width of the particle size distribution is also smaller, which indicates better homogenization with the reflector installed.

\section{REFERENCES}

Deynichenko, G., Samoichuk, K., Yudina, T., Levchenko, L., Palianychka, N., Verkholantseva, V., Dmytrevskyi, D., Chervonyi, V. 2018. Parameter optimization of milk pulsation homogenizer. Journal of Hygienic Engineering and Design, vol. 24, p. 63-67.

Dhankhar, P. 2014. Homogenization fundamentals. IOSR Journal of Engineering, vol. 4, no. 5, p. 1-8. https://doi.org/10.9790/3021-04540108

Di Marzo, L., Cree, P., Barbano, D. M. 2016. Prediction of fat globule particle size in homogenized milk using Fourier transform mid-infrared spectra. Journal of Dairy Science, vol. 99, no. 11, p. 8549-8560. https://doi.org/10.3168/jds.201611284

DSTU 8553. 2015. National Standard of Ukraine (DSTU) Raw milk and cream raw materials. Rules for taking, sampling and preparation for testing.

Fialkova, E. A. 2006. Homogenization. A new look. St. Petersburg : GIORD, 392 p. ISBN 5-98879-032-1.

Floury, J., Desrumaux, A., Lardieres, J. 2000. Effect of high - pressure homogenization on droplet size distributions and rheological properties of model oil - in - water emulsions. Innovative Food Science and Emerging Technologies, 1, p. 127-134. https://doi.org/10.1016/S1466-8564(00)00012-6

Håkansson, A., Fuchs, L., Innings, F., Laszlo, F., Bergenstahl, B., Tragardh, C. 2010. Visual observations and acoustic measurements of cavitation in an experimental model of a high-pressure homogenizers. Journal of Food 
Engineering, vol. 100, no. 3, p. 504-513. https://doi.org/10.1016/j.jfoodeng.2010.04.038

Håkansson, A., Fuchs, L., Innings, F., Revstedt, J., Trägårdh, C., Bergenståhl, B. 2013. Velocity measurements of turbulent two-phase flow in a high-pressure homogenizer model. Chemical Engineering Communications, vol. 200, p. 93-114. https://doi.org/10.1080/00986445.2012.691921

Haponiuk, E., Zander, L., Probola, G. 2015. Effect of the homogenization process on the rheological properties of food emulsions. Polish Journal of Natural Sciences, vol. 30, no. 2, p. $149-158$.

Huppertz, T. 2011. Homogenization of Milk: Other Types of Homogenizer (High-Speed Mixing, Ultrasonics, Microfluidizers, Membrane Emulsification). Encyclopedia of Dairy Sciences: Second Edition, p. 761-764. https://doi.org/10.1016/B978-0-12-374407-4.00226-0

Hussain, H., Truong, T., Bansal, N., Bhandari, B. 2017. The Effect of Manipulating Fat Globule Size on the Stability and Rheological Properties of Dairy Creams. Food Biophysics, vol. 12, no. 1, p 1-10. https://doi.org/10.1007/s11483-016$\underline{9457-0}$

Innings, F., Trägårdh, C. 2005. Visualization of the drop deformation and break-up process in a high pressure homogenizer. Chemical Engineering \& Technology, vol. 28, no. 8, p. 882-891. https://doi.org/10.1002/ceat.200500080

Lawrence, K. D., Klimberg, R. K., Lawrence, S. M. 2009. Fundamentals of forecasting using Excel. New York, N.Y. : Industrial Press, 195 p. ISBN 978-0-8311-3335-1.

Loncin, M., Merson, R. 1979. Food engineering. Principles and selected applications. New York : Academic Press, 279 p. ISBN-10 0124545505.

Nuzhin, E. V., Gladushnyak, A. K. 2007. Homogenization and homogenizers. Odessa : Pechatnyiy dom, 264 p. ISBN 978-966-389-122-4.

Oreshina, M. N. 2010. Pulse dispersion of multicomponent food systems and its hardware implementation : dissertation theses. Moscow, Russia : Moscow State University of Applied Biotechnology. 50 p.

Rayner, M., Dejmek, P. 2015. Engineering aspects of emulsification and homogenization in the food industry. London : CRC Press, Taylor \& Francis Group, 322 p. ISBN 9781466580435. https://doi.org/10.1201/b18436

Rovinsky, L. A. 1994. The analysis and calculation of the efficiency of a homogenizing valve. Journal of Food Engineering, vol. 23, no. 4, p. 429-448. https://doi.org/10.1016/0260-8774(94)90103-1

Samoichuk, K. 2008. Grounding of parameters and modes of work of opposite-flow stream homogenizator of milk : dissertation theses. Donetsk, Ukraine : The Donetsk National University of Economy and Trade named after Mihaylo Tugan-Baranovskiy. 20 p. Available at: https://revolution.allbest.ru/manufacture/00599306_0.html

Samoichuk, K., Kiurchev, S., Oleksiienko, V., Palyanichka, N., Verholantseva, V. 2016. Investigation of homogenization of milk in a pulsation machine with a vibrating rotor. EasternEuropean Journal of Enterprise Technologies, vol. 6, no. 11, p. 16-21. https://doi.org/10.15587/1729-4061.2016.86974

Samoichuk, K., Kovalyov, O. 2013. Analytical parameters of the process of jet homogenization of milk with separate feeding of cream. Proceedings of the Odessa National Academy of Food Technologies, vol. 43, no. 2, p. 77-81.

Samoichuk, K., Zahorko, N., Oleksiienko, V., Petrychenko, S. 2019. Generalization of factors of milk homogenization. In Nadykto, V. Modern development paths of agricultural production. Cham : Springer, p. 191-198. https://doi.org/10.1007/978-3-030-14918-5_21
Samoichuk, K., Zhuravel, D., Viunyk, O., Milko, D., Bondar, A., Sukhenko, Y., Sukhenko, V., Adamchuk, L., Denisenko, S. 2020. Research on milk homogenization in the stream homogenizer with separate cream feeding. Potravinarstvo Slovak Journal of Food Sciences, vol. 14, p. 142-148. https://doi.org/10.5219/1289

Walstra, P., Wouers, J. T. M., Geurts, T. J. 2006. Homogenization. In Dairy science and technology. $2^{\text {nd }}$ ed. Boca Raton, London, New York : Taylor \& Francis Group, LLC, p. 279. ISBN 0-8247-2763-0. https://doi.org/10.1016/j.idairyj.2007.01.001

Yong, A. P., Islam, M. A., Hasan, N. 2017. Effect of pressure on homogenization. Sigma Journal of Engineering and Natural Sciences, vol. 35, no. 1, p. 1-22.

\section{Contact address:}

Kyrylo Samoichuk, Dmytro Motornyi Tavria State Agrotechnological University, Mechanical Engineering Faculty, Department of Processing and Food Production Equipment named after Professor F. Yalpachik, B. Khmelnytskoho Av. 18, 72312, Melitopol, Ukraine, Tel.: +80978805485,

E-mail: samoichuk.k@ukr.net

ORCID: https://orcid.org/0000-0002-3423-3510

Dmytro Zhuravel, Dmytro Motornyi Tavria State Agrotechnological University, Department of Technical Service and Systems in the Agro-Industrial Complex, B. Khmelnytskoho Av. 18, 72312 Melitopol, Ukraine, Tel.: +380968782453,

E-mail: dmytro.zhuravel@tsatu.edu.ua

ORCID: http://orcid.org/0000-0002-6100-895X

Nadiya Palyanichka, Dmytro Motornyi Tavria State Agrotechnological University, Mechanical Engineering Faculty, Department of Processing and Food Production Equipment named after Professor F. Yalpachik, B. Khmelnytskoho Av. 18, 72312, Melitopol, Ukraine, Tel.: +80989875160 ,

E-mail: nonna.2506@gmail.com

ORCID: http://orcid.org/0000-0001-8510-7146

Vadim Oleksiienko, Dmytro Motornyi Tavria State Agrotechnological University, Mechanical Engineering Faculty, Department of Processing and Food Production Equipment named after Professor F. Yalpachik, B. Khmelnytskoho Av. 18, 72312, Melitopol, Ukraine, Tel.: +80970669120 ,

E-mail: vadym.oleksiienko@tsatu.edu.ua

ORCID: http://orcid.org/0000-0002-3438-874X

Serhii Petrychenko, Dmytro Motornyi Tavria State Agrotechnological University, Mechanical Engineering Faculty, Department of Processing and Food Production Equipment named after Professor F. Yalpachik, B. Khmelnytskoho Av. 18, 72312, Melitopol, Ukraine, Tel.: +80964269644 ,

E-mail: petrichenkosw@gmail.com

ORCID: https://orcid.org/0000-0003-3424-5316

Natalia Slobodyanyuk, National University of Life and Environmental Sciences of Ukraine, Faculty of Food Technology and Quality Control of Agricultural Products, Department of Technologies of Meat, Fish and Marine Products, Polkovnika Potekhina Str. 16, 03041 Kyiv, Ukraine, Tel.: +380982768508,

E-mail: slob2210@ukr.net

ORCID: https://orcid.org/0000-0002-7724-2919 
Olga Shanina, Kharkiv Petro Vasylenko National Technical University of Agriculture, Department of Technologies of Processing and Food Industries, Alchevsky Str. 44, 61002, Kharkiv, Ukraine, Tel.: +380509103205,

E-mail: o.shanina.ua@gmail.com

ORCID: https://orcid.org/0000-0003-2465-1257

Ivan Galyasnyj, Kharkiv Petro Vasylenko National Technical University of Agriculture, Department of Technologies of Processing and Food Industries, Alchevsky Str. 44, 61002, Kharkiv, Ukraine, Tel.: +380577730149,

E-mail: ivangalyasnyj@yandex.ru

ORCID: https://orcid.org/0000-0002-4195-9694
Leonora Adamchuk, National University of Life and Environmental Sciences of Ukraine, Faculty of Food Technology and Quality Control of Agricultural Products, Department of Standardization and Certification of Agricultural Products, Polkovnika Potekhina Str. 16, 03041 Kyiv, Ukraine, Tel.: +380976906588,

E-mail: leonora.adamchuk@gmail.com

ORCID: https://orcid.org/0000-0003-2015-7956

*Vladyslav Sukhenko, National University of Life and Environmental Sciences of Ukraine, Faculty of Food Technology and Quality Control of Agricultural Products, Department of Standardization and Certification of Agricultural Products, Polkovnika Potekhina Str. 16, 03041 Kyiv, Ukraine, Tel.: +380668182099,

E-mail: vladsuhenko@gmail.com

ORCID: https://orcid.org/0000-0002-8325-3331

Corresponding author: * 